\title{
PERANCANGAN APLIKASI MEDIA PEMBELAJARAN MELUKIS BANGUN RUANG BERBASIS ANDROID
}

\author{
Nur Rokhman' ${ }^{1}$ Dwi Puji Prabowo², Muslih³ ${ }^{3}$, Noor Hasyim ${ }^{4}$ \\ 1, 2,3,4 Universitas Dian Nuswantoro
}

\begin{tabular}{|l|c|c|}
\hline Received: 16 Januari 2018 & Revised: 8 Maret 2018 & Accepted: 15 Maret 2018 \\
\hline \multicolumn{3}{|c|}{ Available online at: bit.do/demandia }
\end{tabular}

\begin{abstract}
Melukis bangun ruang adalah salah satu materi kelas X Semester 2 yaitu bab ruang dimensi tiga. Dalam materi ini diajarkan bagaimana langkah-langkah menggambar bangun ruang dengan menggunakan pencil, penggaris dan lainnya. Permasalahan sering dihadapi siswa adalah sering lupa langkah-langkahnya karenaketerbatasan jammata pelajaran guru. Android saat ini menjadi sistem operasi smartphone yang paling banyak dipakai oleh banyak orang termasuk siswa tingkat SMA.Penelitian ini bertujuan membuat perancangan aplikasimedia pembelajaran melukis bangun ruang berbasis android bertujuan agar siswa dapat mengulang materi proses melukis bangun ruang. Dalam proses perancangan kami menggunakan metode MDLC (Multimedia Development Life Cycle) yang meliputi 6 tahap yaitu Concept, Design (Perancangan), Obtaining content material, Assembly, Testing dan Distribution. Hasil dari penelitian ini kemudian diterapkan pada smartphone android dan berjalan sesuai yang diinginkan.
\end{abstract}

Kata Kunci : Smartphone, Android, Melukis Bangun Ruang, aplikasi mobile

Abstract: Painting geometry is one of the material at class $X$ of Semester 2 that is available on three dimensional space chapter. This material describes how to draw up the space by using pencil, ruler and others. The problem often faced by students is they often forget the steps because of the limitations of teacher's subject hours. Android is currently the smartphone operating system most widely used by many people including high school level students. This study aims to make the design of learning media applications to build Paint Geometry based android. In the design process we use the method of MDLC (Multimedia Development Life Cycle) which includes 6 stages of Concept, Design (Designing), Obtaining content material, Assembly, Testing and Distribution. The results of this research are then applied to android smart phone and run as desired.

Keywords: Smartphone, Android, Paint Geometry, Mobile Application

Penulis adalah para staf pengajar di Universitas Dian Nuswantoro Semarang, email:

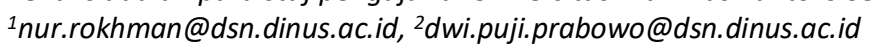




\section{PENDAHULUAN}

Melukis bangun ruang adalah salah satu materi kelas $X$ Semester 2 yaitu bab ruang dimensi tiga. Dalam materi ini diajarkan bagaimana langkah-langkah menggambar bangun ruang dengan menggunakan pencil, penggaris, jangka dan lainnya. Permasalahan sering dihadapi siswa adalah sering lupa langkahlangkahnya karena keterbatasan jam mata pelajaran guru. Selain itu juga dalam materi ini dibutuhkan ketelitian dan daya ingat yang kuat karena banyak sekali langkah-langkah dalam melukis bangun ruang.

Android merupakan sistem operasi yang dikembangkan untuk handphone atau dalam perkembangannya disebut dengan smartphone karena banyaknya layanan yang bisa dijalankan melalui smartphone. Handphone yang awalnya hanya bisa dibuat melakukan panggilan dan sms tapi sekarang seiring kehadiran sistem operasi android bisa bertambah banyak layanan yaitu antara lain games, ebanking, cctv online, bahkan aplikasi remote dan masih banyak lagi.

Jumlah pengguna android di dunia semakin berkembang, bahkan menurut wawai marketing di Indonesia pada tahun 2015 jumlah pengguna Android mencapai 94\% sedangkan 5\% iOS (Adi Fida Rachman, 2015). Hal ini menjadi sebuah peluang yang besar apabila smartphone ini digunakan sebagai media bahan ajar berbasis android. Bahan ajar merupakan bahan atau media untuk mempermudah siswa dalam memahami suatu materi pelajaran di tengah keterbatasan jam sekolah. Dengan adanya media ajar berbasis android diharapkan siswa bisa belajar kapanpun dan dimanapun siswa ingin belajar karena setiap siswa pastinya mayoritas membawa smartphone.

Melukis bangun ruang merupakan suatu kegiatan melukis atau menggambar bangun ruang, dengan berbagai alat sederhana seperti penggaris, jangka, pensil dan penghapus. Biasanya guru di sekolah hanya mencontohkan 
sekali saja, dalam menggambar satu bangun, sehingga siswa yang tidak masuk atau yang ketinggalan langkah-langkahnya akan kebingungan.

Berdasarkan permasalahan tersebut maka dalam penelitian ini akan merumuskan bagaimana membuat aplikasi pembelajaran berbasis android dengan materi melukis bangun ruang dengan metode perancangan MDLC (Multimedia Development Life Cycle). Penelitian ini bertujuan untuk merancang aplikasi berbasis android untuk mempelajari bagaimana langkah melukis bangun ruang dan disertai dengan latihan soal.

\section{KAJIAN TEORI}

Multimedia terdiri dari dua suku kata yaitu multi yang berarti lebih dari satu dan media yang mempunyai alat, wadah atau sarana. Sehingga bisa diartikan multimedia adalah media yang digunakan lebih dari satu dalam menyampaikan informasi. Dalam hal ini, media bisa berupa gambar, audio, teks, video dan grafik yang digunakan secara bersamaan (Darma, 2009 : 17)

Android merupakan sebuah sistem operasi yang meliputi sistem operasi, middleware dan aplikasi berbasis linux. Sistem operasi yang open source ini dibeli oleh Google dari Android Inc yang awalnya dibuat untuk smartphone. Google mengembangkan android ini dengan dibentuknya konsorsium 34 perusahaan perangkat keras, lunak, telekomunikasi dan Handset Alliance (Sunaryo, $2013: 2$ ).

Menggambar atau melukis yaitu kegiatan yang terbentuk dari imajinasi dengan menggunakan teknik dan alat tertentu bisa juga diartikan kegiatan membuat tanda atau pola tertentu di atas permukaan dengan mengolah goresan dari alat gambar (Alwi, 2002:329).

Bangun ruang adalah sebuah bangun geometri dimensi tiga yang mempunyai batas-batas terdiri dari bidang lengkung dan atau bidang datar (Subarinah, 2006: 36). Adapun materi melukis bangun ruang yang diajarkan antara lain balok dan kubus. 


\section{METODE PENELITIAN}

\subsection{Metode Analisis Masalah}

Dalam menganalisis masalah akan digunakan metode analisis framing, metode ini digunakan untuk menganalisis masalah yang terjadi dilapangan. Dalam hal ini, pembelajaran dan media menjadi pokok masalah yang akan dianalisis dan akan menghasilkan rumusan yang akan digunakan dalam perancangan nantinya dengan mempertimbangkan realita yang terjadi, ideal, penyebabnya serta statement yang akan dijadikan kesimpulan dalam analisis nantinya.

Tabel 1. Analisis Data Menggunakan Metode Framing

\begin{tabular}{|c|c|c|c|}
\hline Realita & Ideal & Penyebab & Statement \\
\hline $\begin{array}{l}\text { Siswa sekarang } \\
\text { kurang memahami } \\
\text { bagaimana membuat } \\
\text { bangun ruang dan } \\
\text { istilah-istilah yang } \\
\text { dlam bangun ruang }\end{array}$ & $\begin{array}{l}\text { Siswa memahami } \\
\text { bagaimana cara } \\
\text { membuat bangun } \\
\text { ruang dan istilah- } \\
\text { istilah dalam } \\
\text { bangun ruang }\end{array}$ & $\begin{array}{l}\text { siswa } \\
\text { menganggap sulit } \\
\text { dan kurang } \\
\text { tertarik pelajaran } \\
\text { mengenai bangun } \\
\text { ruang }\end{array}$ & $\begin{array}{l}\text { Diperlukan sebuah } \\
\text { cara mampu } \\
\text { membuat siswa } \\
\text { tertarik mengenai } \\
\text { pelajaran bangun } \\
\text { ruang }\end{array}$ \\
\hline $\begin{array}{l}\text { Metode yang } \\
\text { digunakan dalam } \\
\text { memberikan materi } \\
\text { pelajaran masih } \\
\text { dengan cara lama }\end{array}$ & $\begin{array}{l}\text { Melakukan } \\
\text { pengembangan } \\
\text { cara } \\
\text { pembelajaran } \\
\text { dengan berbagai } \\
\text { cara agar siswa } \\
\text { lebih antusias } \\
\text { dalam belajar }\end{array}$ & $\begin{array}{l}\text { Kurangnya } \\
\text { kemampuan } \\
\text { pengajar dalam } \\
\text { mengembangan } \\
\text { cara } \\
\text { pembelajaran } \\
\text { yang tepat sesuai } \\
\text { dengan } \\
\text { perkembangan } \\
\text { zaman }\end{array}$ & $\begin{array}{l}\text { Diperlukan cara } \\
\text { penyampaian materi } \\
\text { dengan } \\
\text { mengembangkan cara } \\
\text { pembelajaran melalui } \\
\text { berbagai media yang } \\
\text { tepat dan mengena } \\
\text { sesuai dengan } \\
\text { perkembangan zaman }\end{array}$ \\
\hline $\begin{array}{l}\text { Bermain } \\
\text { smartphone(android) } \\
\text { disekolah dianggap } \\
\text { sesuatu yang } \\
\text { negative dilingkungan } \\
\text { sekolah }\end{array}$ & $\begin{array}{l}\text { Smartphone } \\
\text { (android) } \\
\text { digunakan } \\
\text { sebagai sarana } \\
\text { komunikasi dan } \\
\text { belajar siswa } \\
\text { dilingkungan } \\
\text { sekolah sesuai } \\
\text { dengan } \\
\text { perkembangan } \\
\text { zaman }\end{array}$ & $\begin{array}{l}\text { Sebagian siswa } \\
\text { megunakan } \\
\text { smartphone } \\
\text { disekolah untuk } \\
\text { sesuatu yang } \\
\text { negative dan } \\
\text { kurang } \\
\text { bermanfaat }\end{array}$ & $\begin{array}{l}\text { Perlunya } \\
\text { pemanfaatan dalam } \\
\text { penggunaan } \\
\text { smartphone(android) } \\
\text { dilingkungan sekolah } \\
\text { agar siswa dapat } \\
\text { menggunakan } \\
\text { smartphone secara } \\
\text { positif }\end{array}$ \\
\hline
\end{tabular}


Dari data analisis di atas, dapat disimpulkan bahwa perlunya pemanfaatan smartphone (android) di lingkungan sekolah agar siswa dapat menggunakan smartphone dengan positif. Cara yang dilakukan yaitu dengan memberikan materi pelajaran kepada siswa dengan memanfaatkan smartphone(android) dalam bentuk aplikasi pembelajaran sesuai dengan perkembangan zaman.

\subsection{Analisis kebutuhan system}

Dalam perancangan yang dibuat didasarkan pada kebutuhan dilapangan dengan cara survei dan wawancara dengan siswa calon pengguna aplikasi. Kebutuhan system yang dibutuhkan meliputi, materi yang akan dibuat sesuai dengan materi dalam pembelajaran bangun ruang, serta spesifikasi smartphone (android) yang umum digunakan siswa di lingkup sekolah sehingga program nantinya bisa dijalankan disemua android yang dimiliki oleh siswa.

\subsection{Metode perancangan MDLC}

Perancangan yang dilakukan menggunakan metode MDLC dimana dalam perancangan yang dilakukan membutuhkan concept (konsep), design (desain), material collecting (pengumpulan bahan), assembly (pembuatan), testing (pengujian), distribusi (rilis produk)

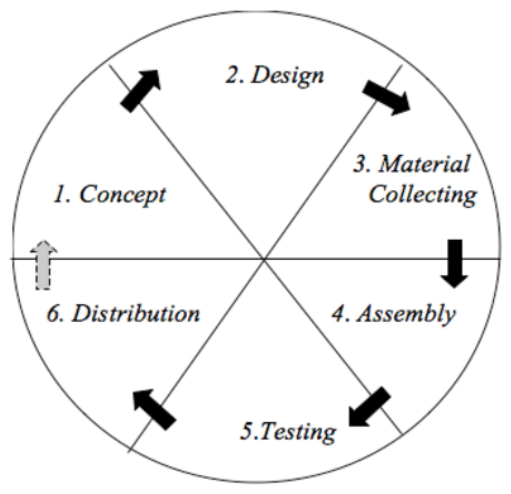

Gambar 1 metode perancangan multimedia Sumber: Sutopo (Binanto, 2010: 260) 
Berikut penjabaran analisis yang dilakukan menggunakan metode perancangan multimedia sebagai berikut:

Tabel 2 Analisis Data Menggunakan Metode Framing

\begin{tabular}{|c|c|c|}
\hline Tahapan & Aspek utama & keterangan \\
\hline Concept (konsep) & $\begin{array}{l}\text { Ide pembuatan aplikasi } \\
\text { pembelajaran }\end{array}$ & $\begin{array}{l}\text { Nama aplikasi : belajar bangun ruang" } \\
\text { Konten : materi pembelajaran mengenai } \\
\text { bangun ruang dan istilah- istilah } \\
\text { didalamnya } \\
\text { Tujuan: membuat siswa mampu } \\
\text { memahami cara membuat bangun } \\
\text { ruang dan mengenal istilah-istilah dalam } \\
\text { bangun ruang }\end{array}$ \\
\hline Design (desain) & $\begin{array}{l}\text { Keseluruhan desain dalam } \\
\text { aplikasi pembelajaran }\end{array}$ & $\begin{array}{l}\text { Jenis multimedia: aplikasi pembelajaran } \\
\text { Model pembelajaran: klik dan drag } \\
\text { Perangkat : android }\end{array}$ \\
\hline $\begin{array}{l}\text { Material collecting ( } \\
\text { pengumpulan bahan) }\end{array}$ & $\begin{array}{l}\text { Pengumpulan bahan } \\
\text { material yang akan } \\
\text { digunakan dalam aplikasi }\end{array}$ & $\begin{array}{l}\text { Materi mengenai bangun ruang yang } \\
\text { dipelajari siswa disekolah. } \\
\text { Karakter yang digunakan seorang siswa } \\
\text { dengan mengacungkan jempol yang } \\
\text { mempunyai arti bahwa siswa yang } \\
\text { berprestasi. }\end{array}$ \\
\hline $\begin{array}{l}\text { Assembly } \\
\text { (pembuatan) }\end{array}$ & $\begin{array}{l}\text { Pembuatan asset dan } \\
\text { coding dalam aplikasi }\end{array}$ & $\begin{array}{l}\text { Aset : membuat aset karakter, perlatan, } \\
\text { pensil, penggaris, jangka, ikon-ikon } \\
\text { navigasi } \\
\text { Desain background : menggunakan } \\
\text { warna yang soft } \\
\text { Sound : menggunakan music yang } \\
\text { mampu merangsang otak dan membuat } \\
\text { nyaman pengguna } \\
\text { Animasi: membuat animasi untuk } \\
\text { tutorial yang dirancang didalam aplikasi } \\
\text { Coding : melakukan coding agar aplikasi } \\
\text { yang dibuat bisa berjalan dengan baik }\end{array}$ \\
\hline Testing (pengujian) & $\begin{array}{l}\text { Melakukan pengujian } \\
\text { pada aplikasi }\end{array}$ & $\begin{array}{l}\text { Menguji navigasi pada tampilan } \\
\text { Menguji animasi pada tutorial apa } \\
\text { sudah bisa dijalankan } \\
\text { Menguji latihan soal evaluasi yang } \\
\text { sudah dibuat } \\
\text { Menguji sound yang telah dipasang } \\
\text { Menguji }\end{array}$ \\
\hline Distribution & $\begin{array}{l}\text { Menyalurkan aplikasi } \\
\text { pembelajaran ke target } \\
\text { audien }\end{array}$ & $\begin{array}{l}\text { Mendistribusikan aplikasi yang telah } \\
\text { diuji ke target untuk melihat respon } \\
\text { yang didapatkan setelah menggunakan } \\
\text { aplikasi pembelajaran yangtelah dibuat. }\end{array}$ \\
\hline
\end{tabular}




\section{HASIL DAN DISKUSI}

Dalam visualisasi yang digunakan dalam aplikasi ini menggunakan gambar berbasis vektor

Tabel 3. Visualisasi asset

Sumber: Rokhman dkk, 2018
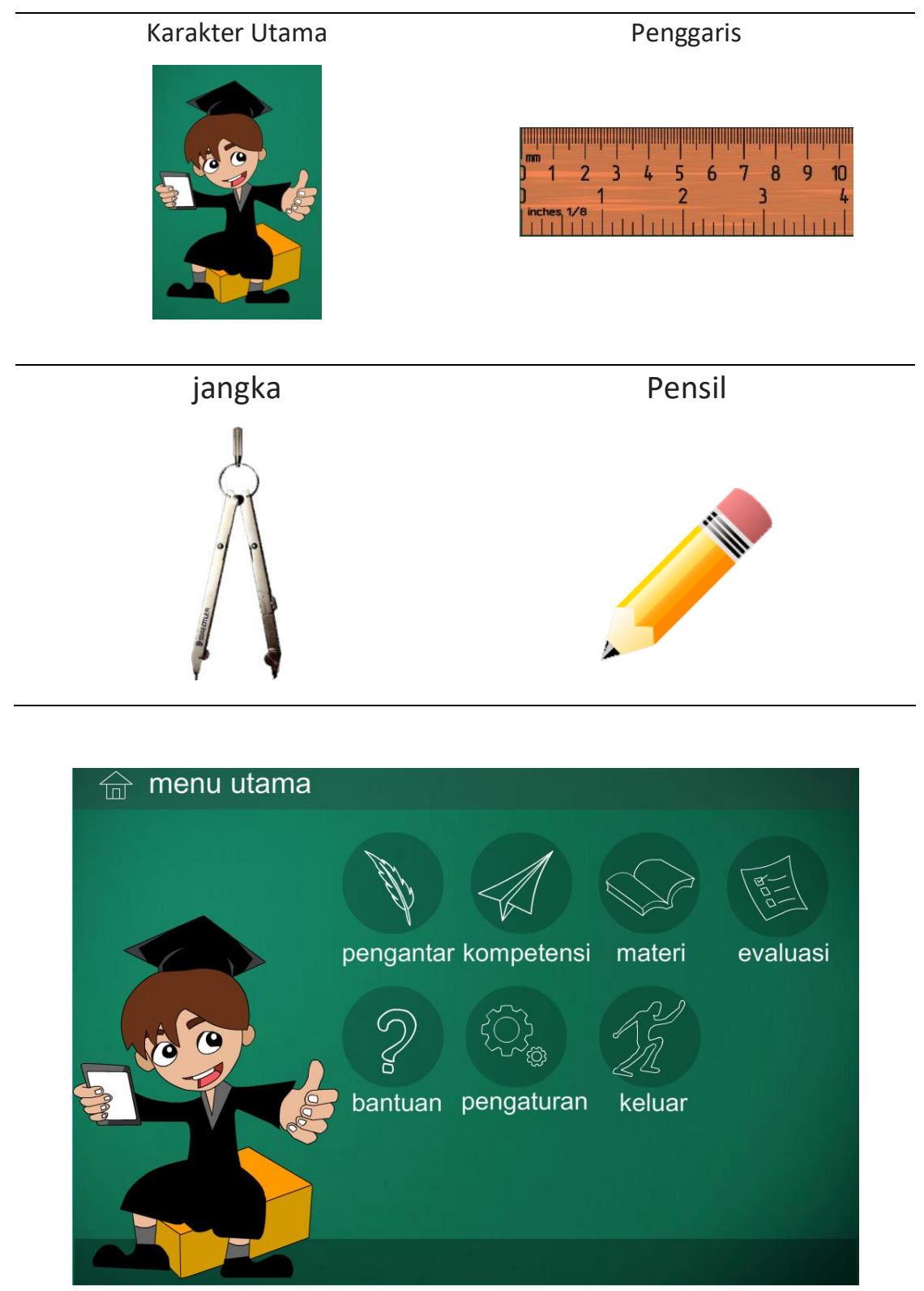

Gambar 2. Tampilan awal menu utama 

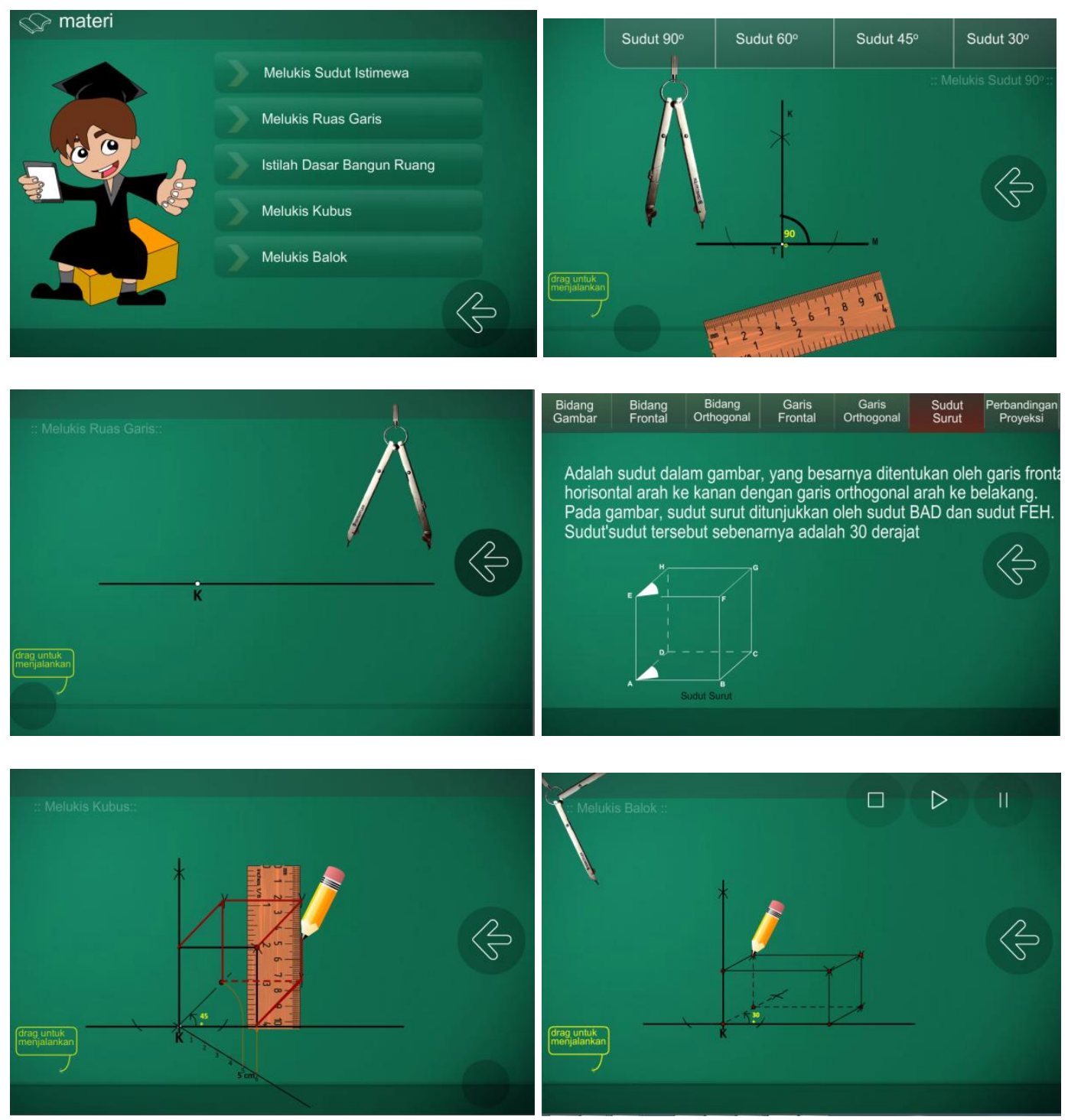

Gambar 3 tampilan menu materi

Sumber: Rokhman dkk, 2018

Pada menu materi terdapat materi-materi yang dirancang untuk memberikan pembelajaran pada siswa yang di dalamnya terdapat 5 sub menu pembelajaran diantaranya adalah cara membuat sudut istimewa, melukis ruas garis, istilah- 
istilah dasar dalam bangun ruang, melukis kubus dan melukis balok mengunakan peralatan yang disediakan. Di dalam materi yang disampaikan dalam aplikasi dibuat interaktif sehingga siswa dapat tertarik dengan aplikasi yang telah dibuat. Selain itu dengan menggunakan gambar, pembelajaran ini kan memberi pengalaman dalam mempelajari sesuatu hal sehingga siswa pun bisa mengingat dan mengaplikasikanya secara langsung.

Pada proses pembelajaranya, materi yang disampaikan dalam 5 sub materi pembelajaran bangun ruang sebagai berikut :

1. Siswa diajarkan bagaimana cara membuat garis istimewa dari sudut 30 derajat, 45 derajat, 60 derajat serta sudut istimewa 90 derajat sehingga pembelajaran ini akan menjadi dasar siswa dalam membuat bangun ruang nantinya.

2. Siswa diajarkan cara membuat ruas garis dengan benar sehingga ketika dalam keadaan nyata siswa dapat membuat ruas garis dengan benar sesuai dengan apa yang mereka pelajari di aplikasi

3. Siswa diajarkan dan dikenalkan istilah-istilah dasar bangun ruang seperti bidang gambar, bidang frontal, bidang orthogonal, garis frontal, garis orthogonal, sudut surut dan perbandingan projek sehingga istilah-istilah dasar pada bangun ruang bisa dimengerti dengan baik oleh siswa.

4. Siswa diajarkan bagaimana cara membuat bangun ruang kubus dengan benar dan detail.

5. Siswa diajarkan bagaimana cara membuat bangun ruang balok dengan benar dan detail. 

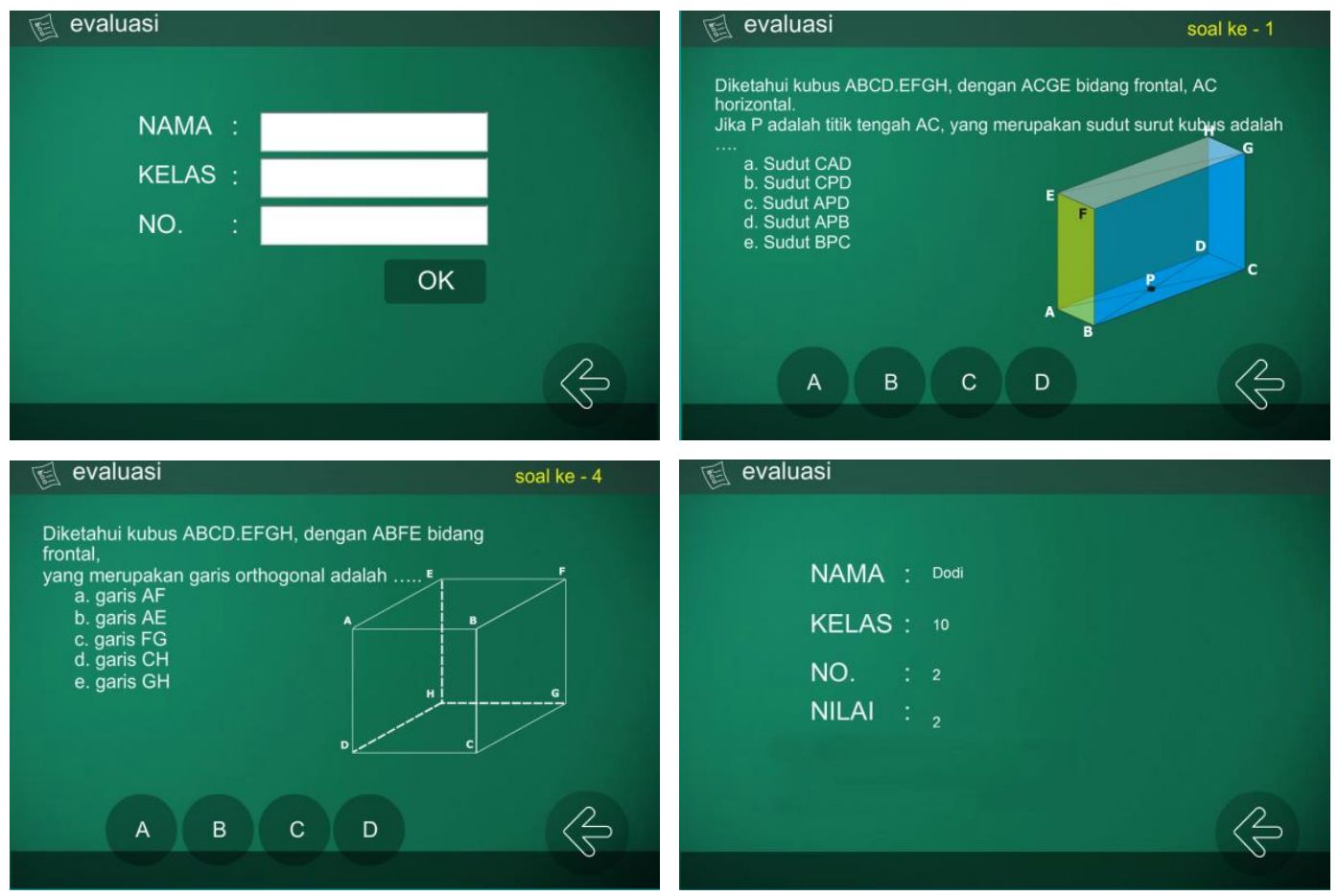

Gambar 4 tampilan menu evaluasi Sumber: Rokhman dkk, 2018

Pada menu evaluasi ini digunakan untuk mengetahui pemahaman siswa terhadap materi bangun ruang yang disajikan, dimana evaluasi yang dilakukan dengan menjawab 10 soal yang disediakan. Setiap soal yang dijawab akan bernilai 1 point, bila 10 soal terjawab dengan benar maka akan mendapatkan 10 point dan itu artinya siswa memahami materi mengenai bangun ruang. Setelah dilakukan sample testing aplikasi pada 10 siswa ternyata pemahaman siswa terhadap materi yang mendapatkan nilai 60 keatas mencapai $70 \%$ dan hanya $30 \%$ yang kurang memahami dan mendapatkan nilai 50 kebawah.

\section{KESIMPULAN DAN SARAN}

Berdasarkan uraian hasil penelitian yang telah dibahas maka dapat diambil kesimpulan bahwa aplikasi pembelajaran berbasis android merupakan salah satu solusi dalam pengembangan pembelajaran untuk siswa-siswi di sekolah. Aplikasi media pembelajaran yang menarik akan membuat siswa lebih mudah memahami materi yang disampaikan, serta tampilan yang menarik akan memberikan sebuah 
pengalaman visual yang mampu melekat didalam otak lebih lama sehingga siswasiswi dapat mengaplikasikanya dalam pembelajaran disekolah. Pemberian evaluasi dalam system aplikasi akan memberikan sebuah evaluasi bagi siswa untuk mengetahui seberapa tingkat pemahaman mereka terhadap bangun ruang dan aplikasi yang telah dibuat ternyata memberi dampak positif serta membantu siswa dalam belajar bangun ruang.

Adapun aplikasi belajar bangun ruang yang telah dibuat ternyata masih memiliki kekurangan sehingga kedepannya masih bisa untuk disempurnakan dengan melengkapi dengan berbagai jenis bangun ruang lainnya seperti prisma tegak segitiga, limas segitiga, limas segiempat, limas segi lima, limas segi enam, tabung, kerucut, dan bola.

\section{DAFTAR PUSTAKA}

Buku dan jurnal

Darma, J. S. 2009. Buku Pintar Multimedia, 1st ed. Jakarta: MediaKita, 2009.

Hasan Alwi. 2002. Kamus Besar Bahasa Indonesia, 2nd ed. Jakarta: Depdiknas.

Sri Subarinah. (2006). Inovasi Pembelajaran Matematika SD. Jakarta: Depdiknas.

S. Sunaryo, A. Handojo, and J. Andjarwirawan. 2013. "Pembuatan Aplikasi Wisata Sejarah Pertempuran Surabaya 1945 Berbasis Android," J. Infra, vol. 1, pp. $1-2$.

Internet

Adi Fida Rachman, M 2015, Android Kuasai Asia Tenggara di Indonesia Paling Juara, viewed 08 January 2018, <https://inet.detik.com/consumer/d3054169/android-kuasai-asia-tenggara-di-indonesia-paling-juara> 